\title{
SYSTEM OF MANAGEMENT OF EDUCATIONAL PROCESS BY MEANS OF THE INFORMATION AND EDUCATIONAL ENVIRONMENT
}

\section{Dotsenko Nataliiia ${ }^{1}$}

DOI: https://doi.org/10.30525/978-9934-571-89-3_14

Modernization of institutions of higher education highlights the informatization of education. Information and communication technologies certainly belong to high technologies and its improvement and widespread adoption is referred within priority areas of scientific and technological development of Ukraine until 2020 by the legislation [1, p. 23]. The main task is the creation of the informational and educational environment as a system for managing the educational process by means of the information and educational environment. The information and educational environment is a systematically organized set of data transmission, information resources, interoperability protocols, hardware-software and organizational and methodological support, aimed at satisfying the needs of users in information services and resources of educational nature. The informational and educational environment should be understood as a single information and educational space, built with the integration of information on traditional and electronic media, computer and telecommunication interaction technologies, which includes virtual libraries, distributed databases, teaching and learning complexes and advanced apparatus of didactics [2, p. 5].

\footnotetext{
${ }^{1}$ Mykolayiv National Agrarian University, Ukraine
} 
The informational and educational environment of an educational institution of higher education includes:

- a complex of informational educational resources, including digital educational resources;

- a set of technological means of information and communication technologies: computers, communication channels;

- a system of modern pedagogical technologies that provide training in the modern information and educational environment [3, p. 387].

In order to study the course in an informational and educational environment, higher education applicants use interactive electronic learning tools, such as: multimedia presentations for practical work, electronic test training simulators, online laboratory works with multimedia support, interactive audiovisual lectures, online glossary, etc..The obtained results are evaluated using statistical indicators, which include: the frequency of viewing educational content, the frequency of visits, the index of ease and the effectiveness of discrimination (Figure 1).

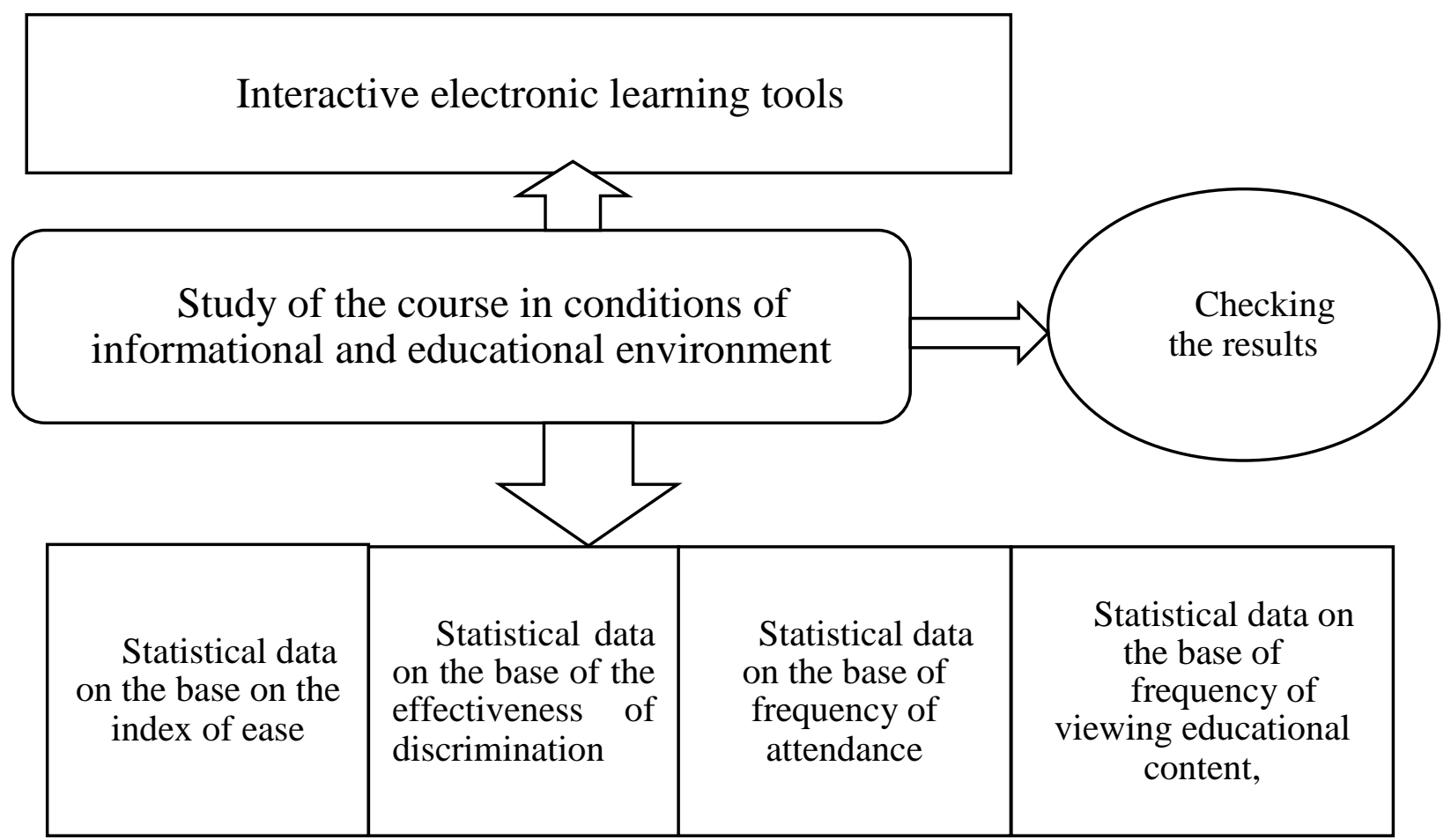

\section{Figure 1. Implementation of educational process management in the conditions of informational and educational environment}

The index of ease is an index for comparing the simplicity of task. This indicator is the ratio of the average score obtained by applicants for higher education to the maximum number of points for the assignment. This indicator is a measure of difficulty level for higher education applicants [4]. The index of discrimination is an indicator of the ability of a specific task to separate more successful performers. In general, the subjects are divided into three groups: well-trained, medium and poorly trained. Each group includes one third of the total number of subjects. This parameter can take values between +1 (all subjects from the strong group responded correctly, 
and the weak ones were incorrect) and -1 (all the test subjects from the strong group answered incorrectly, and the weak ones, on the contrary, correctly). The negative value of the index indicates that the weak applicants of higher education respond to this question better than strong ones. Such tasks should be discarded. In fact, they reduce the accuracy of the entire assessment procedure.

The coefficient of discrimination is the correlation coefficient between the set of values of the answers received by the applicants of higher education when answering a specific question, with the results of their task as a whole. This parameter can also accept values between 1 and -1 . Positive values are consistent with the issues that are really highlighted by well-educated higher education applicants, while the negative value of the ratio indicates that poorly trained higher education applicants are on average better suited to this issue than well-trained. Such tasks should be avoided. The advantage of the coefficient of discrimination compared with the index of discrimination lies in the fact that the first uses information from the whole population of higher education, and not only the critical upper and lower thirds of this population.

Consequently, the management of the educational process by means of the information and educational environment is carried out using statistical indicators, which include: frequency of viewing educational content, frequency of attendance, index of ease and effectiveness of discrimination. On the basis of the data obtained, it is possible to regulate the educational content.

\section{References:}

1. Bulletin of Supreme Consul of Ukraine (VVR). 2011, no 4, p. 23.

2. Bykov V.Yu. (2006). The theoretical and methodological grounds for modeling of educational environment of modern pedagogic systems. Information Technologies and Learning Tools, vol. 1, p. 3-11.

3. Shevchuk Ye., Shpak A. (2007). Experience practice of introduction innovative technologies into educational and management activities of the university. Proceedings III International Conference "Strategy of Quality in Industry and Education", Varna, Bulgaria, Scientific Journal of the Technical University of Varna, vol. 2, p. 386-389.

4. Quiz reports. URL: http://docs.moodle.org./19/en./Quiz_reports\#Item_analysis 